\title{
Development of MIMO antenna with decoupling structure for ultra-wideband application
}

\author{
Muhammad Aslam Hasin, M. T. Ali, Hamizan Yong, Bazilah Baharom, Hadi Jumaat
}

Antenna Research Centre (ARC), Faculty of Electrical Engineering, University Teknologi Mara (UiTM), Malaysia

\begin{tabular}{l}
\hline \hline Article Info \\
\hline Article history: \\
Received Jan 19, 2019 \\
Revised Apr 20, 2019 \\
Accepted May 16, 2019 \\
\hline
\end{tabular}

\section{Keywords:}

Decoupling structure High isolation antenna Orthogonal radiator UWB MIMO antenna

\begin{abstract}
This paper presents the design of a double-sided Multiple-Input MultipleOutput (MIMO) antenna with a decoupling structure for Ultra-WideBand (UWB) applications. The proposed antenna consists of four square radiating elements printed on FR-4 substrate with partial slotted ground. The substrate consists of two sides and each side are consisting of two slotted partial ground and two square radiator antennas. The elements of the front side are orthogonal to the elements of the back side because it was to increase the isolation of the antenna. The front and back sides of the substrate were also presented with the decoupling structure to avoid the mutual coupling of each antenna. The results of simulated and measured of the proposed UWB MIMO antenna are observed and analyzed. The objective of the UWB MIMO antenna was achieved that large bandwidth of return loss below than $10 \mathrm{~dB}$ from $3.3 \mathrm{GHz}$ to $11 \mathrm{GHz}$ with an insertion loss lower than $-20 \mathrm{~dB}$ within the required frequency band. The proposed MIMO antennas exhibits a nearly Omni-directional radiation pattern with average gain value $4.36 \mathrm{dBi}$.
\end{abstract}

Copyright () 2019 Institute of Advanced Engineering and Science. All rights reserved.

\author{
Corresponding Author: \\ Muhammad Aslam Bin Hasin, \\ Antenna Research Centre (ARC), \\ Faculty of Electrical Engineering, \\ University Teknologi MARA (UiTM), \\ 40450, Shah Alam, Selangor Darul Ehsan, Malaysia. \\ Email: aslam7484@gmail.com
}

\section{INTRODUCTION}

In the development of modern communication, the ultra-wide band (UWB) technology play an interest to the researcher since the high data rate demand with a limited range in lower power spectral level [1] in order to protect the interference of UWB system from other existed wireless systems [2-3]. In numerous wireless applications, the technology of UWB becomes more tempting and bring attention to all researchers as the Federal Communication Commission (FCC) released the ultra-wide band (UWB) technology that operates from 3.1 to $10.6 \mathrm{GHz}$ [1-2]. Larger bandwidth with stable radiation, compact size, and low profile are the challenges in order to design UWB antenna [5-7]. Moreover, when dealing with the compact size of the MIMO antenna, it will introduce mutual coupling that will limit the channel capacity of the system [4-6]. Multiple-input Multiple-output (MIMO) technology was used to overcome the Multipath fading that is one of the main problems that causes the performance of the UWB system to be downgraded [11-13]. The distance between elements of the MIMO system should be more than half lamda of the lowest operating frequency in order to avoid the mutual coupling between elements [14-16]. However, this method also increases the size of the MIMO antenna. For the proper performance in a MIMO system, the isolation between elements must be less than $-15 \mathrm{~dB}$ [14], [17-18].

In this paper, four elements have been mounted on a $4 \mathrm{~cm} \times 4 \mathrm{~cm}$ on a FR4 substrate of compact MIMO_UWB antenna. This is done to ensure that the allocated bandwidth for application of UWB from 3.3 $\mathrm{GHz}$ until $11.0 \mathrm{GHz}$ has been satisfy. After decoupling structure between elements on the top and bottom 
layers has been placed, the insertion loss exceeds $-20 \mathrm{~dB}$ has been achieved throughout the entire UWB frequency. The antenna was designed, optimized and simulated using CST Microwave Studio software. The antenna measurement system was used to measure the impedance and radiation of experimentally fabricated antenna characteristics. The proposed MIMO-UWB antenna was confirmed of having a wider impedance bandwidth and higher isolation by the simulated and measured results performance thus make it appropriate for the UWB systems.

\section{RESEARCH METHOD}

\subsection{The Single Element of UWB Antenna}

The single-element of the ultra-wideband antenna is shown in Figure 1. The antenna with small size $2 \mathrm{~cm}$ x $2 \mathrm{~cm}$ was designed and simulated by using CST Microwave Studio 2015. The FR-4 was used as the substrate material of the antenna with dielectric-constant $=4.4$ and thickness $=1.6 \mathrm{~mm}$. From Figure 1(a), it shows that the microstrip patch antenna consists the square shape of radiating element and the microstrip line feed as the feeding method was chosen since it is simple to match and easy to analyze [19-20]. From Figure 1 (b), it shows that the back view of the antenna that consists of the partial ground with a slotted rectangular shape in order to increase the bandwidth of the antenna [21-23]. The simulated result of the return loss of the single-element of the antenna is shown in Figure 2. From Figure 2, it shows that the antenna has a large bandwidth of $6.7 \mathrm{GHz}$ that can operate from frequency of $4.3 \mathrm{GHz}$ to $11 \mathrm{GHz}$ with the magnitude of return loss below than $-10 \mathrm{~dB}$ between that range. Therefore, it was claimed that the range of operating frequency of the antenna was the ultra-wideband.

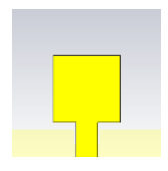

(a) Front view

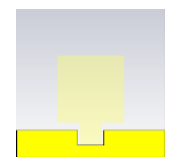

(b) Back view

Figure 1. 2D structure of the UWB single antenna

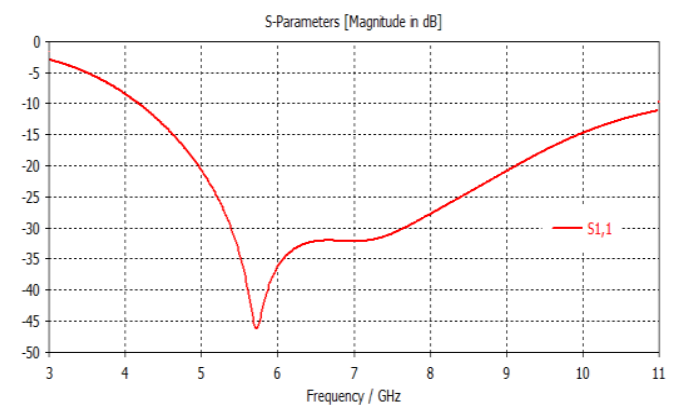

Figure 2. Return loss $[\mathrm{dB}]$ of single antenna

\subsection{The Multi-Element of UWB Antenna}

The multi-element of the ultra-wideband antenna is shown in Figure 3. The single-element design from Figure 1 was duplicated into four elements to make the multi-element of UWB antenna. The same design and material of the substrate are used that makes the size of the antenna increase to $4 \mathrm{~cm} \mathrm{x} 4 \mathrm{~cm}$. From Figure 3, it shows that the double-sided antenna with the arrangement of each element is orthogonal to each other. Two square radiating elements which are port 1 and port 2 shows in Figure 3(a) was placed at the front of the antenna and another two square radiating elements, port 3 and port 4 are placed at the back side of the antenna as shown at Figure 3(b). The multiple radiating elements of the antenna for the ultra-wideband application is called UWB_MIMO antenna. 


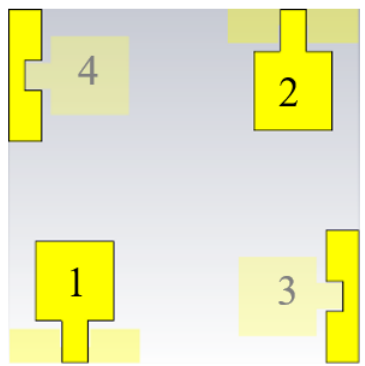

(a) Front view

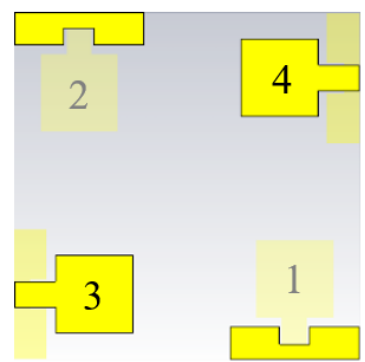

(b) Back view

Figure 3. 2D structure of the UWB_MIMO antenna

The simulated result of s-parameter for UWB_MIMO antenna shown in Figure 4. Based on Figure 4(a), it clearly shows that the return loss with a magnitude below than $-10 \mathrm{~dB}$ is from $4 \mathrm{GHz}$ to $10.4 \mathrm{GHz}$ with a bandwidth of $7 \mathrm{GHz}$. It also shows that the operating frequency for all port $(1,2,3,4)$ is similar since it is the same design. The insertion loss $[\mathrm{dB}]$ for UWB_MIMO antenna is shown in Figure 4(b). From Figure 4(b), it is obviously shows that the insertion loss $[\mathrm{dB}]$ between port 1 to port $2(\mathrm{~S} 1,2)$, port 1 to port $3(\mathrm{~S} 1,3)$, and port 1 to port $4(\mathrm{~S} 1,4)$ is below than $-15 \mathrm{~dB}$ for all operating frequency which means the good isolation between radiating element.

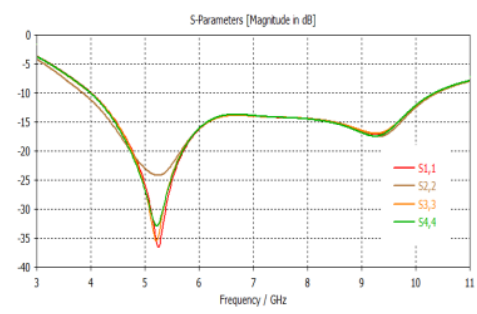

(a) Return loss at port 1

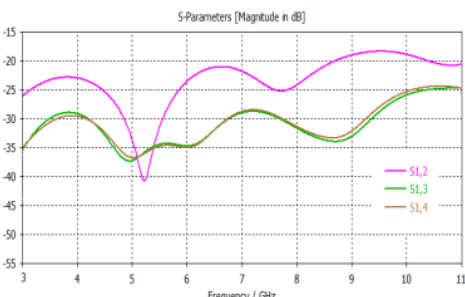

(b) Insertion Loss at port 1

Figure 4. S-Parameter of the UWB_MIMO antenna

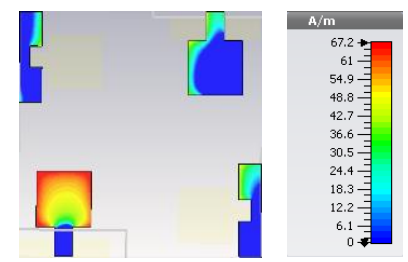

Figure 5. Surface current distribution of the antenna Port 1 at $5.25 \mathrm{GHz}$

The distribution of the surface current between each element was observed in Figure 5. Based of Figure 5, it shows that when port 1 is excited, the amount of surface current also distributes to the port 2 . This situation was known as mutual coupling since the antenna has a multi-radiating element on a compact size of the antenna [24-26]. When dealing with MIMO, it also deals with the mutual coupling that will affect the performance of UWB_MIMO antenna.

\subsection{The Proposed UWB_MIMO Antenna with Decoupling Structure}

The decoupling structure is one of the methods to prevent the antenna from the mutual coupling [2728] that detected in Figure 5. The proposed UWB_MIMO antenna with the decoupling structure was shown in Figure 6 and the parameter of each shape also shown in Table 1. From Figure 6, it shows that the decoupling structure consists of four rectangular removed slots in order to block the distribution of surface 
current to other port. As seen in Figure 6(a), it shows that the decoupling structure is connecting to the partial_slotted ground at port 3 and 4. While the decoupling structure on the back side of the antenna was connected to the partial_slotted ground at port 1 and 2 is shown in Figure 6(b). The purpose of connected the decoupling structure to the ground is to neutralize the surface current and increase the gain of the antenna.

Table 1. The Dimensions of the Proposed UWB_MIMO Antenna

\begin{tabular}{cccccccccc}
\hline $\mathrm{W}_{1}$ & $\mathrm{~W}_{2}$ & $\mathrm{~W}_{3}$ & $\mathrm{~W}_{4}$ & $\mathrm{~W}_{5}$ & $\mathrm{~W}_{6}$ & $\mathrm{~L}_{1}$ & $\mathrm{~L}_{2}$ & $\mathrm{~L}_{3}$ & $\mathrm{~L}_{4}$ \\
\hline 40 & 9 & 3.943 & 17.5 & 3.5 & 1 & 4.75 & 3.75 & 2 & 5 \\
\hline
\end{tabular}

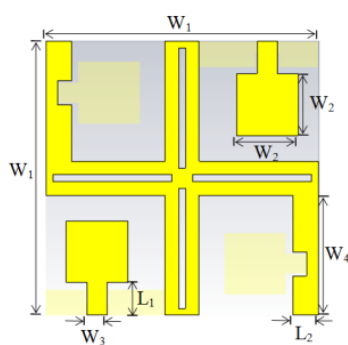

(a) Front view

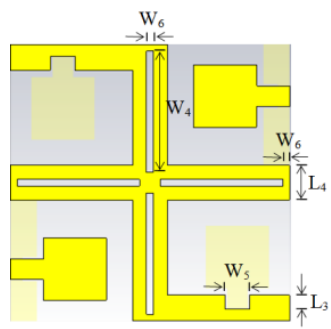

(b) Back view

Figure 6. 2D structure of the proposed UWB_MIMO antenna

The simulated result of S-Parameters is shown in Figure 7. From Figure 7(a), it shows that the return loss that below than $-10 \mathrm{~dB}$ is from $3.3 \mathrm{GHz}$ to $11 \mathrm{GHz}$ for all port $(1,2,3,4)$. It is proved that return loss signal pattern is similar between each other port and the bandwidth also increase by $7.7 \mathrm{GHz}$. Figure 7(b) and 7(c) also show the insertion loss of the proposed UWB_MIMO antenna. From Figure 7(b), it shows that when port 1 is excited and another port is connected to $50 \Omega$ matched load, the isolation is below than $-20 \mathrm{~dB}$ for entire operating frequency. The same result also notice at Figure 7(c) when the excitation at port 2, 3, and 4 , the isolation also below than $-20 \mathrm{~dB}$ for the entire operating frequency.

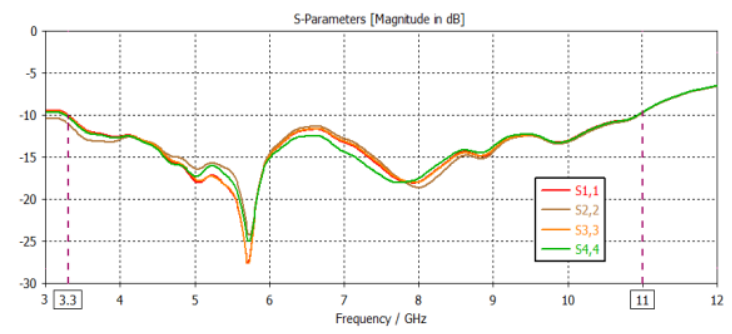

(a) Return loss $[\mathrm{dB}]$ of the proposed UWB_MIMO antenna for port 1, 2, 3, and 4

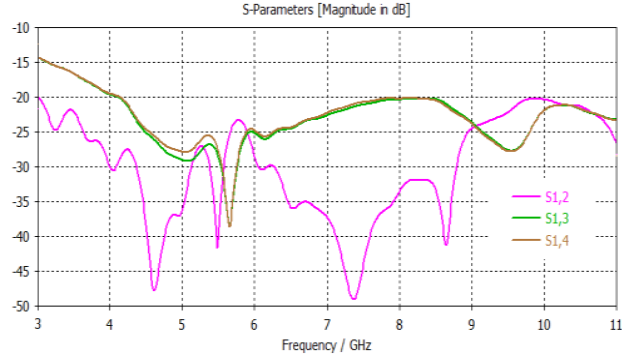

(b) The insertion loss $[\mathrm{dB}]$ excitation at port 1

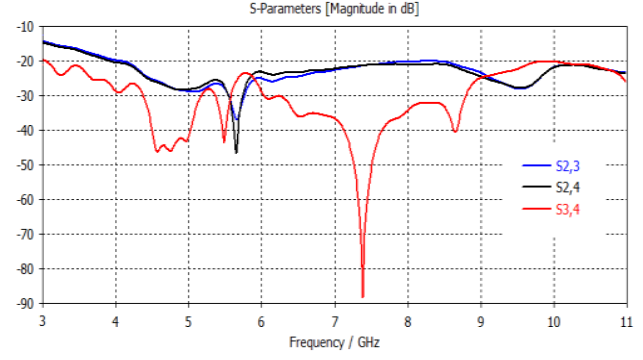

(c) The insertion loss $[\mathrm{dB}]$ excitation at port 2, 3, 4

Figure 7. S-Parameter of the proposed UWB_MIMO antenna 
The surface current of the proposed UWB_MIMO antenna at $5.7 \mathrm{GHz}$ of port 1 was shown in Figure 8. From Figure 8, it clearly can be noticed that when antenna 1 is excited, the surface current did not distribute to the port 2. It shows that the design of the decoupling structure reduces the mutual coupling of the MIMO antenna. The comparison of simulated gain before and after applying the decoupling structure is shown in Figure 9. From Figure 9, it can be concluded that the decoupling structure also increases the gain of the antenna.
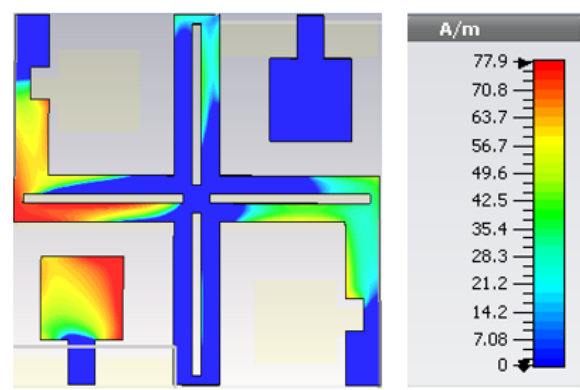

Figure 8. Surface current distributions of the proposed UWB_MIMO antenna at $5.7 \mathrm{GHz}$

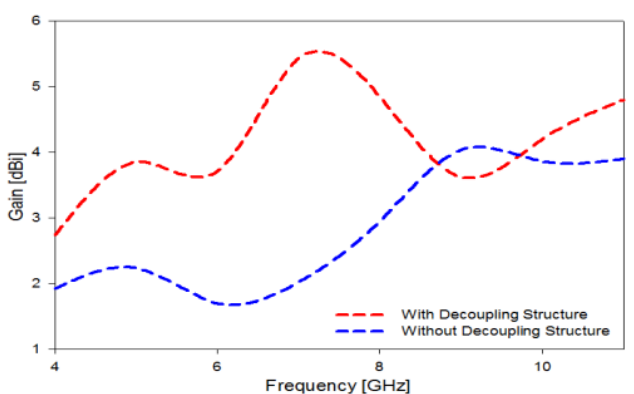

Figure 9. The simulated gain of the antenna at port 1 with and without using the decoupling structure

\section{RESULTS AND ANALYSIS}

\subsection{Performance Measurement of the Proposed UWB_MIMO Antenna}

The FR-4 board is chosen as the substrate material of the antenna with dielectric-constant $=4.4$ and thickness $=1.6 \mathrm{~mm}$. The final design has been fabricated as shown in Figure 10. From Figure 10, the antenna was soldered to a $50 \Omega$ SMA connector port for connect to the external devices such as measurement devices.

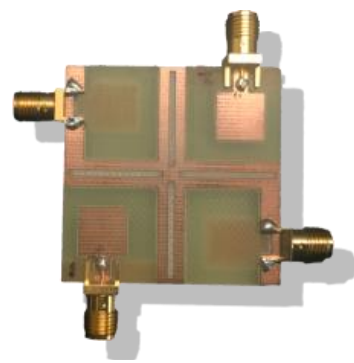

(a) Front view

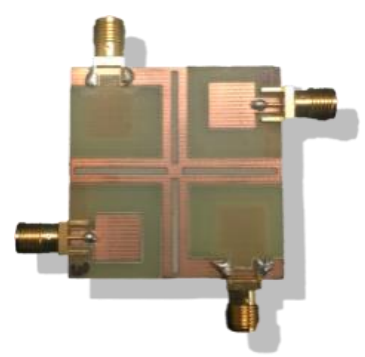

(b) Back view

Figure 10. The fabricated of the proposed UWB_MIMO antenna

The magnitude of S-Parameters of the antenna has been tested by using Vector Network Analyzer (VNA) and the comparison between simulated and a measurement result are shown in Figure 11. From Figure 11(a), it shows that the measured proposed UWB_MIMO antenna with a magnitude that below $-10 \mathrm{~dB}$ can operate from $5.6 \mathrm{GHz}$ to $12.8 \mathrm{GHz}$ for all port $(1,2,3,4)$ with the bandwidth of $7.2 \mathrm{GHz}$. The return loss of the measured was shifted to the right compared to the simulated result due to error accuracy of the fabrication process. The size of a radiated element on fabricated MIMO antenna was decreased by a few millimeters during the fabrication process. Therefore, the operating frequency of UWB_MIMO antenna also changes from $5.6 \mathrm{GHz}$ to $12.8 \mathrm{GHz}$. Theoretically, the smaller size of the radiating element will increase the frequency. From Figure 11(b), it shows the insertion loss of measured result is below than $-18 \mathrm{~dB}$ for all operating frequency which means that it is good isolation between elements. 


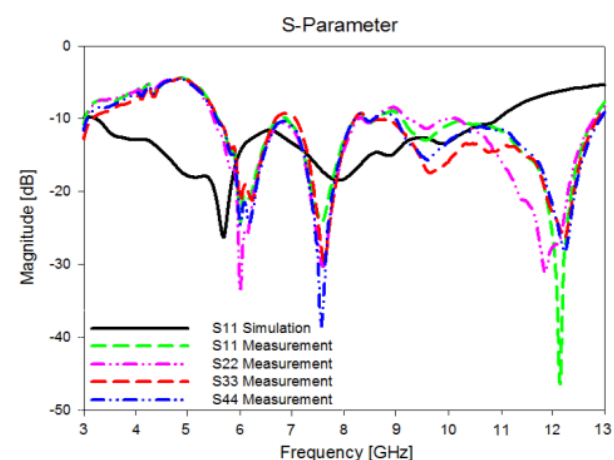

(a) The return loss

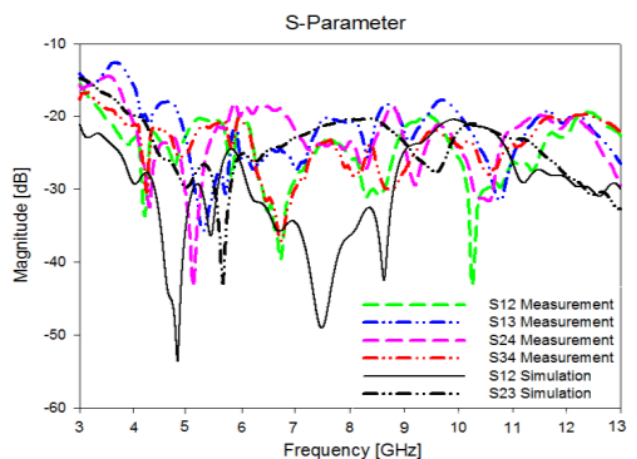

(b) The Insertion loss

Figure 11. The S-Parameters of the proposed UWB_MIMO antenna

The radiation pattern measurement has been done using a chamber room with a range of operating frequency from $6 \mathrm{GHz}$ to $11 \mathrm{GHz}$. The 2D polar plot of the radiation pattern at frequency $6 \mathrm{GHz}, 7.5 \mathrm{GHz}$, and $9.5 \mathrm{GHz}$ are shown in Figures 12, 13 and 14. From Figures 12, 13 and 14, it shows three different planes of simulated and measured for the radiation pattern. The measured result is quite similar to the simulated result that has the radiation pattern nearly to the omnidirectional that is good for UWB application.

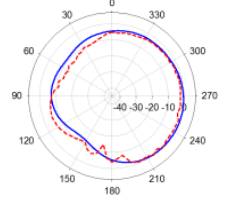

(a) XZ_Plane

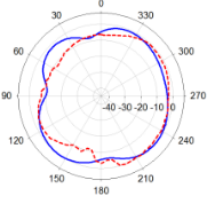

(b) YZ_Plane

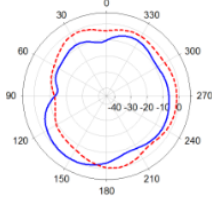

(c) XY_Plane

Measuremen

Simulation

Figure 12. The 2D polar plot radiation pattern at $6 \mathrm{GHz}$ of port 1 for proposed UWB_MIMO antenna

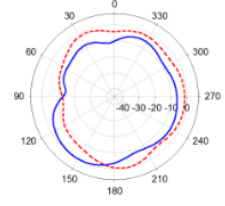

(a) XZ_Plane

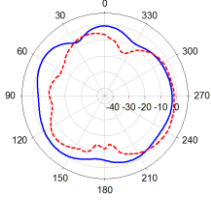

(b) YZ_Plane

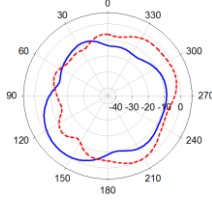

(c) XY_Plane

Measurement

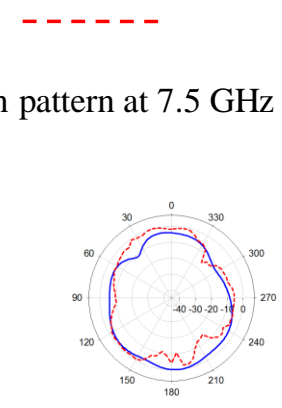

(b) YZ_Plane
Simulation

Simulation

Figure 13. The 2D polar plot radiation pattern at $7.5 \mathrm{GHz}$ of port 1 for proposed UWB_MIMO antenna

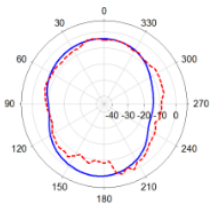

(a) XZ_Plane Measurement

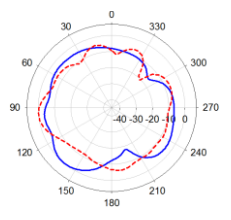

(c) XY_Plane

Figure 14. The 2D polar plot radiation pattern at $9.5 \mathrm{GHz}$ of port 1 for proposed UWB_MIMO antenna 
The comparison between the measured and simulated peak gain is shown in Figure 15. Since the simulated operating frequency is from $3.3 \mathrm{GHz}$ to $11 \mathrm{GHz}$ while the measured operating frequency is from $5.6 \mathrm{GHz}$ to $12.8 \mathrm{GHz}$, therefore the range of operating frequency from $6 \mathrm{GHz}$ to $11 \mathrm{GHz}$ is chosen because it is easy to compare. From Figure 15, it shows that the peak gain of simulated and measured was similar. The average gain for measured is $4.36 \mathrm{dBi}$ while the average gain for simulated is $4.44 \mathrm{dBi}$.

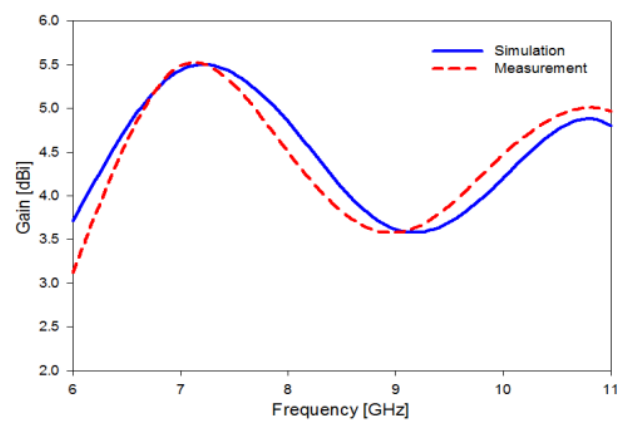

Figure 15. The peak gain of simulated and measured UWB_MIMO antenna

\section{CONCLUSION}

Development of MIMO Antenna with decoupling structure for Ultra-Wideband Application has been proposed with small size $4 \mathrm{~cm} \times 4 \mathrm{~cm}$. Each radiating elements and ground are orthogonal to each other for both sides of the substrate. The decoupling structure has been designing and connected to the two-slotted partial ground at both sides of the substrate to decrease the mutual coupling and increase the gain performance of the antenna. The simulated and measured result has been observed and analyzed in term of the reflection coefficient, insertion loss, surface current, gain, and radiation pattern to see the performance of the antenna. The bandwidth for simulated and measured was within $7 \mathrm{GHz}$ is achieved, hence, it is still in the criteria of the ultra-wideband application. The insertion loss of simulated and measured antenna is below than $-18 \mathrm{~dB}$ for the entire operating frequency with the average gain value $4.36 \mathrm{dBi}$.

\section{ACKNOWLEDGEMENTS}

The author would like to give appreciation to Antenna Research Centre (ARC), Faculty of Electrical Engineering, Universiti Teknologi MARA (UiTM), for providing facilities to conduct the present research. Special thanks to all staff of Antenna Research Centre (ARC) that involved during the measurement in the laboratory, to those who contribute so much effort, whether direct or indirect and support throughout the research progress.

\section{REFERENCES}

[1] J. S. Sheu, S. H. Lyu, and C. Y. Huang, "On antenna orientation for inter-cell interference coordination in cellular network MIMO systems," J. Commun. Networks, vol. 18, no. 4, pp. 639-648, 2016.

[2] K. Qian and L. Zhao, "An Integrated Antenna Interference Cancellation Chip With Frequency Rejection Characteristic for MIMO Systems," IEEE Antennas Wirel. Propag. Lett., vol. 16, pp. 1285-1288, 2017.

[3] W. A. Ellatif, D. A. El Aziz, and R. Mahmoud, "A 4-elements performance analysis of compact UWB antenna for MIMO-OFDM systems," Proc.-WiSEE 20162016 IEEE Int. Conf. Wirel. Sp. Extrem. Environ., pp. 135-139, 2016.

[4] A. A. Ibrahim and R. M. Shubair, "Reconfigurable band-notched UWB antenna for cognitive radio applications," Mediterr. Microw. Symp., no. October, 2017.

[5] M. Alibakhshi-Kenari and M. Naser-Moghadasi, "Novel UWB miniaturized integrated antenna based on CRLH metamaterial transmission lines," AEU-Int. J. Electron. Commun., vol. 69, no. 8, pp. 1143-1149, 2015.

[6] W. A. E. Ali and A. A. Ibrahim, "A compact double-sided MIMO antenna with an improved isolation for UWB applications,” AEU-Int. J. Electron. Commun., vol. 82, pp. 7-13, 2017.

[7] M. M. Islam, M. T. Islam, M. R. I. Faruque, N. Misran, M. Samsuzzaman, M. I. Hossain, and T. Alam, "A compact disc-shaped super wideband patch antenna with a structure of parasitic element," Int. J. Appl. Electromagn. Mech., vol. 50, no. 1, pp. 11-28, 2016.

[8] B. Baharom, M. T. Ali, A. Awang, and H. Jaafar, "Effect of Slot Structure in Isolation of a Closely- spaced PIFA MIMO Antenna Design for Future 5G Applications." 
[9] M. T. A. Baharom B, "Multiple-element PIFA MIMO antenna system design for future $5 G$ wireless communication applications," Asia-Pacific Microw. Conf. Proceedings, APMC, pp. 0-3, 2017.

[10] B. Baharom, M. T. Ali, H. Jaafar, and H. Yon, "Dual-Element of high-SHF PIFA MIMO Antenna for Future $5 G$ Wireless Communication Devices,” Proc. - 2018 Int. Symp. Antennas Propag., no. ISAP, pp. 151-152, 2018.

[11] S. Gautam and K. Cecil, "A Four-Element Planar UWB-MIMO Antenna System Comprising of Plus-Sign Stub for High Isolation,” no. 5, pp. 17-20, 2018.

[12] L. Dong, H. Choo, R. W. Heath, and H. Ling, "Simulation of MIMO channel capacity with antenna polarization diversity," IEEE Trans. Wirel. Commun., vol. 4, no. 4, pp. 1869-1872, 2005.

[13] A. Singal and D. Kedia, "Performance Analysis of Antenna Selection Techniques in MIMO-OFDM System with Hardware Impairments: Energy Efficiency perspective," Int. J. Electr. Comput. Eng., vol. 8, no. 4, pp. 2272-2279, 2018.

[14] N. K. Kiem, H. N. B. Phuong, and D. N. Chien, "Design of compact $4 \times 4$ UWB-MIMO antenna with WLAN band rejection," Int. J. Antennas Propag., vol. 2014, 2014.

[15] A. Altaf, M. A. Alsunaidi, and E. Arvas, "A novel EBG structure to improve isolation in MIMO antenna," 2017 Usn. Radio Sci. Meet. (Joint with AP-S Symp. Usn. 2017, pp. 105-106, 2017.

[16] A. Sharma, K. P. Kalaskar, and J. R. Gangane, "Analysis of MIMO antennas with parasitic elements for wireless applications,” 2016 IEEE Int. Conf. Comput. Intell. Comput. Res. ICCIC 2016, vol. 1, pp. 1-4, 2017.

[17] B. Yang, M. Chen, and L. Li, "Design of a four-element WLAN/LTE/UWB MIMO antenna using half-slot structure," AEU - Int. J. Electron. Commun., vol. 93, pp. 354-359, 2018.

[18] A. Salh, L. Audah, N. S. M. Shah, and S. A. Hamzah, "Adaptive Antenna Selection and Power Allocation in Downlink Massive MIMO Systems,” Int. J. Electr. Comput. Eng., vol. 7, no. 6, pp. 3521-3528, 2017.

[19] A. Arora, A. Khemchandani, Y. Rawat, S. Singhai, and G. Chaitanya, "Comparative study of different feeding techniques for rectangular microstrip patch antenna," Int. J. Innov. Res. Electr. Electron. Instrum. Control Eng., vol. 3 , no. 5, pp. 32-35, 2015 .

[20] A. Kumar, J. Kaur, and R. Singh, "Performance Analysis of different feeding techniques," Int. J. Emerg. Technol. Adv. Eng., vol. 3, no. 3, pp. 884-890, 2013.

[21] A. BOUTEJDAR, "Novel Microstrip Antenna Aims at UWB Applications," no. October, pp. 62-65, 2015.

[22] M. R. Zaman, M. T. Islam, N. Misran, and J. S. Mandeep, "Analysis of resonance response performance of C-band antenna using parasitic element," Sci. World J., vol. 2014, 2014.

[23] W. A. E. Ali and A. A. Ibrahim, "A compact double-sided MIMO antenna with an improved isolation for UWB applications," AEU - Int. J. Electron. Commun., vol. 82, pp. 7-13, 2017.

[24] A. Hagras, T. A. Denidni, and M. Nedil, "Reduction of mutual coupling between millimeter-wave cylindrical DRA using a soft surface for mimo applications," IEEE Antennas Propag. Soc. AP-S Int. Symp., pp. 1532-1533, 2014.

[25] M. Lin, P. Liu, and Z. Guo, "Gain-enhanced Ka-band MIMO antennas based on the SIW corrugated technique," IEEE Antennas Wirel. Propag. Lett., vol. 16, pp. 3084-3087, 2017.

[26] A. A. Isaac, H. M. Al-Rizzo, A. I. Hammoodi, S. Abushamleh, and H. R. Khaleel, "Isolation enhancment of two planar monopole antennas for MIMO wireless applications," IEEE Antennas Propag. Soc. AP-S Int. Symp., vol. 2015-Octob, pp. 380-381, 2015.

[27] Y. Wu and Y. Long, "A High Isolation MIMO Antenna without Decoupling Structure for LTE $700 \mathrm{MHz}$," Int. J. Antennas Propag., vol. 2015, 2015.

[28] A. Choudhary, “A Review Paper on MIMO Antenna Isolation Improving Techniques," Journals Int. Shodh Eng. Technol., vol. 02, no. 2, 2017.

\section{BIOGRAPHIES OF AUTHORS}

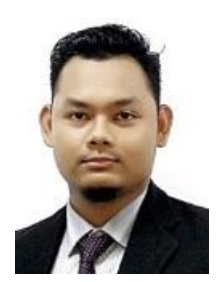

Muhammad Aslam Hasin was born in Kuala Terengganu on February 17, 1995. He received the Diploma in Electrical Engineering (Power) from Universiti Teknologi MARA (UiTM) Dungun, Terengganu, Malaysia in 2015. In 2019, he completed his Bachelor Degree in Electronic Engineering (Communication) from Universiti Teknologi MARA (UiTM) Shah Alam, Selangor, Malaysia. Now he is working as Research Assistant at Antenna Research Centre (ARC) Faculty of Electrical Engineering, Universiti Teknologi MARA.

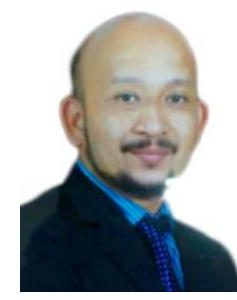

Mohd Tarmizi Ali received the B.Eng. degree in electrical engineering from the Universiti Teknologi Mara (UiTM), Shah Alam, Malaysia, in 1996, the M.Sc. degree in electrical engineering from the University of Leeds, Leeds, U.K., in 2002, and the Ph.D. degree in electrical engineering from the Universiti Teknologi Malaysia (UTM), Johor, Malaysia, in 2010. On October 2018, he has been a Professor with the Faculty of Electrical Engineering (FKE), UiTM, and since 2011 he has been appointed as the Group Leader of the Antenna Research Center (ARC), FKE UiTM. He is a senior member for the IEEE and the member for the Antenna Propagation/Microwave Theory and Technology/Electromagnetic Compatibility (AP/MTT/ECM) Joint Chapter. His research interests include the areas of communication antenna design, radio astronomy antennas, satellite antennas, and electromagnetic radiation analysis. 


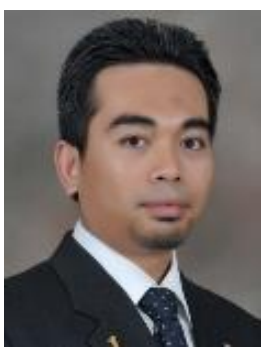

Hamizan Yon was born in Muar Johor on February 07, 1980. He received the Bachelor Information Technology with Network Computing from Open University Malaysia in 2013. In 2017, he completed his Master in Electrical Engineering (Communication) with Antenna Research Centre (ARC) Faculty of Electrical Engineering, Universiti Teknologi MARA. Now he pursuing his PhD at Antenna Research Centre (ARC) Faculty of Electrical Engineering, Universiti Teknologi MARA. In 2009 he join Universiti Teknologi MARA at Shah Alam campus as Assistant Lecturer. Active in research activates, he is one of the members of fundamental research grant (FRGS) under Minister of Higher Education and UiTM Lestari grant. As academician, Hamizan also member of The Institution of Engineering and Technology that actively presenting and publishing research activities at national and international levels.

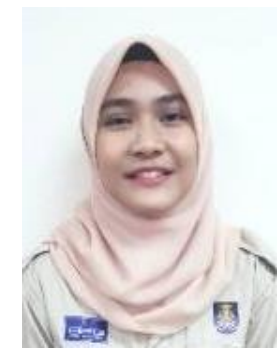

Bazilah Baharom born in Penang, Malaysia on September 5, 1994. She received a Bachelor Engineering degree (HONS) Electronic Engineering from Universiti Teknologi MARA, Malaysia in 2018. Now she pursuing her Master of Science (Electrical Engineering) at Antenna Research Centre (ARC) Faculty of Electrical Engineering, Universiti Teknologi MARA. Currently, she is active in research activities and interests are on antennas and she is one of the members of a fundamental research grant (FRGS) under Minister of Higher Education grant

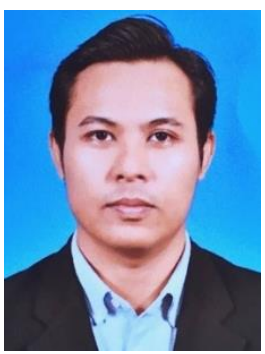

Hadi Jumaat is a student at the Universiti Teknologi MARA (UiTM), Selangor, Malaysia. He received the B. degree in engineering electronics (communication) (2012) and M.Sc. degree in electrical engineering (2015) from the Universiti Teknologi MARA (UiTM), Selangor, Malaysia. He is currently working towards the Ph. D. degree in electrical engineering at Universiti Teknologi MARA. His research interests are in communication antenna design. 